\title{
Expert evidence in cases of child abuse
}

\author{
Catherine Williams
}

In a recent case in the High Court, $\operatorname{Re} R,{ }^{1} \mathrm{Mr}$ Justice Cazalet laid down some very important guidelines for the benefit of experts in civil cases of child abuse. It is most important that medical personnel be aware of the content of the guidelines if called upon either to prepare a report or to act as a witness in court.

It is vital that medical experts should be aware of the very different nature of child abuse proceedings from other sorts of cases. In particular it is necessary to distinguish between civil cases of child abuse and criminal proceedings concerned with establishing the guilt or innocence of an alleged offender. Criminal proceedings are highly adversarial. The welfare of the child is not the main issue. Although the expert in a criminal trial is supposed to be evenhanded in his approach, ${ }^{2}$ the whole conduct of the case is radically different.

The guidelines in $\operatorname{Re} R$ are directed to the expert who is involved in a civil case of child abuse. In one of the reported decisions arising out of the Cleveland crisis Mr Justice Hollis stated that it should be remembered that 'no person is on trial here, not the parents nor anyone connected with the family or children'. ${ }^{3}$ This message has been reinforced by Lord Justice Butler-Sloss on a number of occasions. She has repeatedly stated the view that child abuse cases should be primarily looked upon as inquisitorial rather than adversarial. ${ }^{4}$ The importance of this is that everyone should be aware that it is not appropriate to 'take sides' in child abuse cases. Rather, it is the duty of all to strive to reach a decision which is for the welfare of the child. This is a duty imposed on the court $^{5 \star}$ and this duty also reflects on experts.

An expert may become involved in child abuse proceedings in a number of different ways. A representative of the local authority social service department may bring the child for examination, because it is suspected that abuse is taking place. The parents of a child may ask for assistance in defending themselves against allegations of abuse. A guardian ad litem, appointed by the court to represent the child, may request the expert's opinion. Experts, themselves, may effectively initiate proceedings by drawing the local authority's attention to the child. It does not matter how experts become involved. Their duty is the same in all the examples described.

If an expert is asked to examine a child physically he or she should be aware of the new limitations on examination contained in the rules accompanying the Children Act 1989. These state, in Rule $4.18,{ }^{6}$ that ' $[\mathrm{No}]$ person may, without the leave of the court, cause the child to be medically or psychiatrically examined, or otherwise assessed, for the purpose of the preparation of expert evidence for use in the proceedings'. These limitations arose out of disquiet at the number of examinations children had undergone, particularly in cases of alleged sexual abuse. The rules are thus designed to limit any physical assessment of the child to the absolute minimum necessary.

However, in many instances the expert will not be asked to see the child, but to review and give an opinion on the child's notes. Despite the fact that child abuse proceedings are intended as inquisitorial rather than adversarial, many of the parties involved in such cases still treat the issue in an adversarial fashion. Having asked the expert to give an opinion, if that opinion does not coincide with the views it is hoped would be expressed, parties may simply commission another report, and not use the original report. This is an area where doctors could take a lead in encouraging more openness and a more truly inquisitorial approach. Experts are entitled to say that they will agree to review the material, but only on condition that the report is subsequently disclosed to all parties involved in the case. Provided this condition is agreed to any report is no longer bound by confidentiality. Thus, even if the instructing party then failed to disclose the report experts would be at liberty to do so themselves. In an extreme case the expert may be able to breach confidentiality as of right, but this will only be so where public policy so demands. This could arise if the child would otherwise be placed in grave danger. ${ }^{?}$ Insisting on full disclosure is likely to lead to protests, not just by lawyers acting for parents suspected of abuse but by local authorities as well. However, doctors could try and establish good practice in this way and help to further the inquisitorial approach.

\section{The guidelines}

In his guidance to experts, Mr Justice Cazalet stated three basic propositions that they should adhere to always, either in the preparation of a written report or in giving evidence in court. He said experts should: '(a) provide a straightforward, not a misleading opinion; (b) be objective and not omit factors which do not support their opinion; and (c) be properly researched'. ${ }^{8}$

The position of experts is a special one, as they are particularly privileged in law. All witnesses 
are, of course, entitled to state the facts as they know them. However, only experts are then allowed to go on to give an opinion in evidence. The court can, and may well, give great weight to this opinion. This makes experts central characters in much of the decision making process. Consequently they should be very conscious of their privileged role and respect the obligations that come attached to it.

\section{The guidelines considered}

\section{(a) EXPERTS SHOULD PROVIDE A}

STRAIGHTFORWARD, NOT A MISLEADING OPINION The major obligation that attaches to the role of experts is that they must be aware that they are involved in a case as independent persons. This means that they must present arguments in a fashion that they truly believe to be as near as possible to the objective truth, not as a partisan biased in favour of one side or the other. No expert should seek to promote any particular case. As was stated in $R e R$ 'opinions can, of course, differ and indeed quite frequently experts who have expressed their objective and honest opinions will differ, but such differences are usually within a legitimate area of disagreement'. ${ }^{8}$ However, Mr Justice Cazalet later goes on to say: '[If] contrary to the appropriate practice an expert does provide a report which is other than wholly objective - that is one which seeks to 'promote' a particular case - the report must make this clear. However, such an approach should be avoided because, in my view, it would: (a) be an abuse of the expert's proper function and privilege; and (b) render the report an argument, and not an opinion' .

Experts obviously are involved in pursuing theories, in research, and in trying to persuade the rest of the medical profession of the validity of their conclusions. However, a court is not a suitable forum in which to advance untested hypotheses. The place for that kind of debate is in the medical literature and in conferences and meetings, where others, who are eminently well qualified to do so, may challenge any findings. Judges and magistrates are not in such a position. They must take much of the expert evidence presented to them on trust. As Mr Justice Cazalet stated: 'outside the legal field the court itself has no expertise and for that reason frequently has to rely on the evidence of experts'. Consequently, if an expert believes that current medical opinion on, for example, the occurrence of fractures in babies, is subject to challenge, he or she should present their arguments to medical peers for scrutiny. Only after there has been such scrutiny, followed by acceptance of the validity of the expert's argument, should such evidence then be presented in a court.

The Cleveland report' highlights an example of where it was felt that experts may have been too ready to take a published hypothesis and develop it to diagnose sexual abuse in children in a way not intended by the authors of the original paper. ${ }^{10}$ In commenting on this the inquiry team quoted at length ( $p$ 203) from a letter written by Professor Forfar, then President of the British Paediatric Association, which they thought made some wise and helpful suggestions. He wrote: 'The regulation of medical practice is achieved best when it is accomplished within the medical profession. New stances based on a new awareness of clinical signs, or new significances being attached to them, require first to be established within the profession. This takes some time and requires persuasion and scientific evidence of validity, based on the accepted method of communication to professional journals or scientific meetings. It is the dedicated research worker and the pioneering enthusiast who so often change medicine for the better and uncover deficiencies in medical practice and understanding. In the end however, any new development has to be fitted into the complex jigsaw which constitutes balanced medical practice. As well as the benefits, the possible adverse effects of any revision of accepted practices have to be taken into account. Child sexual abuse is a very serious matter which we as paediatricians must seek to eliminate, but removal of children from their parents and forced institutionalism is anther very serious matter. The values which different paediatricians and child psychiatrists will attach to these will vary. Perhaps, more importantly, any mistake in pursuing correction of one will cause the other'.

It is clear from this that the Cleveland inquiry team were of the opinion that an expert's hypothesis untested or not accepted by medical peers should not be presented as evidence in court.

The Cleveland report ${ }^{9}$ also provides a clear example of where there were serious concerns about the polarisation of views, with, it was felt, experts identifying themselves too closely with one side. The inquiry team were told that a coauthor of a paper in the Lancet $^{10}$ describing the reflex anal dilatation test 'had herself become more cautious, and she urged caution in her evidence. From her own experience she tried to give good advice to proceed slowly, [but] without success'. (See Cleveland report p 199.) The team criticised another of the doctors involved, who, they said, 'appeared to have become associated with the cause of the parents and was unable to provide us with the cool, detached and considered testimony the Inquiry might have expected of the expert ...' (See Cleveland report p 201.)

Another notorious child abuse incident occurred, shortly after Cleveland, in Rochdale. In this instance it was alleged that children were being involved in 'satanic abuse'. The children were made wards of court. When the issue was heard in court, Mr Justice Douglas Brown was very severe in his criticism of one of the expert witnesses relied upon by the local authority. He commented ' $[I]$ did not think that she had that detachment which the court expects of an expert witness. I agree completely with [the doctor who] said of her that "anything that did not fit she explained away. If the evidence supported her theory she would use it and if it didn't she would discredit it". That was, in my view, her consistent approach throughout her evidence'." Not surprisingly after such criticism, the judge went on to prefer the evidence of other experts on every point.

One message of Cleveland, Rochdale, and 
$R e R$ is absolutely clear. To be a valuable expert witness and to be listened to with respect the expert must not put forward untested or unacceptable views, and must be prepared to cast aside ideas of loyalty to one party or another and give evidence with the child's welfare as the primary aim.

(b) EXPERTS SHOULD BE OBJECTIVE AND NOT OMIT FACTORS WHICH DO NOT SUPPORT THEIR OPINION Clearly selectivity of material in an expert's report may lead to what would appear to be an unbiased report becoming a misleading one. This selectivity can be crucial both in informing preliminary decision making or in influencing the outcome of final proceedings.

In cases of child abuse affidavit evidence is frequently used for interim proceedings. It may well also be used in emergency ex parte applications. It is obvious that any court hearing these applications must have correct information if it is to make the right order, pending a full hearing. The consequences of a 'wrong' decision may be very serious in such cases. Deciding to leave a child at home who is then subject to further abuse is a 'wrong' decision. But, removing a child from home who has not been subject to abuse may be just as damaging. In Rochdale, social workers were so anxious to ensure that preliminary orders were made removing the children from home, that they omitted highly relevant material. Mr Justice Douglas Brown, in the full wardship hearing, found that the affidavits of both Miss X and Miss Y were inaccurate and in places seriously misleading, with the result that the judge was substantially misled on each occasion. Thus he comments, at p 230, 'Important matters were omitted. A said that she had never seen B's ghost and that nothing horrible was happening to her and she would certainly tell social workers and her parents if it were. Neither statement is reflected in the affidavit'. While appreciating they had a difficult job to perform the judge was nevertheless quite clear that omitting material must not be allowed. He said 'Affidavits, particularly affidavits for use in an ex parte hearing, should be drawn with care and should be accurate, balanced and fair, and ... should contain material, if known, which militates against the relief sought'. (See Rochdale BC $v$ A at pp 2312.)

If experts are requested to prepare a report in anticipation of being called as a witness in a full hearing, they must equally not mislead by omission. Quite apart from the obvious consequence that as a result a court may be misled into reaching a decision which is not in the welfare of the child, other consequences may also flow. By failing to consider properly all the material the expert is in danger of inhibiting the proper assessment of a case and discouraging the parties' advisers from pursuing avenues which should have been followed up. A misleading opinion might lead parties to develop or have confirmed false views and hopes about the potential success of their case. Such an opinion may well lead to greatly increased costs, by provoking the other side to bring their own expert evidence to counter what is being said; had the report been a proper one it might have proved to be a noncontentious issue and acceptable to all sides.

Whether the expert has supplied affidavit evidence or supplied a full report for the court, what the court expects and wants is an explanation of how the expert has reached any opinions expressed. This may well involve including alternative hypotheses or opposing views. Experts can then explain why it is that they have reached a particular opinion. This will then greatly assist the court in assessing the strength of the experts' evidence.

\section{(c) EXPERTS SHOULD BE PROPERLY RESEARCHED}

In saying experts should be 'properly researched', Mr Justice Cazalet was not addressing his mind to the issue that an expert should be well read and have kept up with current medical literature, although this is obviously expected of all experts. Rather he was closely allying this requirement to the other two requirements and looking at the issue of researching the particular individual case. Experts are routinely instructed by one of the parties to a case. This may well lead to them being presented with very different basic information from that given to an expert instructed by the other side. But this does not mean that experts should proceed to give an opinion without reference to their source of information. An expert should always be alert to the fact that the information provided may have been selective. If experts feel that their opinion is not properly researched, as they suspect that they have been given insufficient data, then their duty is to say so, and to indicate that as a result the opinion can be no more than a provisional one.

\section{Conclusion}

Doctors acting as expert witnesses have sometimes been ineffective in court because they have not understood properly their responsibility. As a witness of fact the doctors' role is obvious simply to state the facts as they know them. However, whenever doctors are asked for an opinion they are acting as expert witnesses. They can then expect to be respected by the court only if they take a properly informed, well balanced, non-partisan view of the events.

\section{Re R [1991] 1 FLR 291}

? R v Maguire [1992] 94 Cr App R 133

3 Cleveland CC v A; Cleveland CC v B [1988] 2 FCR 593 at

4598 . $2 \operatorname{Re} M[1990] 2$ FLR 36 at p 39.

5 Children Act 1989. London: HMSO 1989. S $1(1)$

6 Family Proceedings Rules 1991, SI 1991/1247 r.4.18 which applies in the County Court and High Court. For the applies in the County Court and High Court. For the magistrates' court see the Family Proceedings
(Children Act 1989) Rules 1991, SI 1991/1395 r.18.

7 W v Egdell [1990] 1 All ER 1089.

7 W v Egdell [1990] 1 All ER 1089.
8 Re R [1991] 1 FLR 291 at p 292.

8 Re R [1991] 1 FLR 291 at p 292. utler-Sloss E. Report of the inquiry into child at

1987. London: HMSO, 1988. (Cm 412.)

10 Hobbs C, Wynne J. Buggery in childhood - a common syndrome in child abuse. Lancet 1986; ii: 792-6.

11 Rochdale Borough Council v A [1991] 2 FLR 192 at p 218. 